\title{
The effects of different electron donors on anaerobic nitrogen transformations and denitrification processes in Lake Taihu sediments
}

\author{
Donghong Wang • Qinghui Huang • \\ Chunxia Wang $\cdot$ Mei Ma $\cdot$ Zijian Wang
}

(C) Springer Science+Business Media B.V. 2007

\begin{abstract}
Nitrogen transformations in anaerobic sediments and leachate in Lake Taihu were simulated in the laboratory. Ammonium, nitrate and nitrite were analyzed after incubation under anaerobic conditions. Different reductive states and $\mathrm{pH}$ values were obtained by using different electron donors, such as glucose, sucrose, potato starch and sodium acetate. Chemical nitrogen transformation mechanisms were discussed relative to physico-chemical properties of lake sediment. Results demonstrated that nitrogen transformations in anaerobic conditions supplemented with different electron donors varied, and supplementation with certain electron donors may enhance nitrogen removal from anaerobic sediments. Among the four electron donors studied, higher nitrogen removal efficiencies were observed with acetate and starch. Saccharides, such as glucose, sucrose and starch, stimulate nitrate reduction to nitrite, while acetate stimulates nitrate reduction to ammonium.
\end{abstract}

Guest editors: B. Qin, Z. Liu \& K. Havens

Eutrophication of shallow lakes with special reference to Lake Taihu, China

D. Wang - Q. Huang - C. Wang - M. Ma .

Z. Wang $(\bowtie)$

State Key Laboratory of Environmental Aquatic Chemistry, Research Center for Eco-Environmental

Sciences, Chinese Academy of Sciences, Shuangqing

Road, Haidian District, Beijing 100085, China

e-mail: zjwang@mail.rcees.ac.cn
Keywords Electron donor - Anaerobic . Nitrogen · Transformation - Sediment - Lake Taihu

\section{Introduction}

Denitrification is a microbial process that converts nitrate to nitrogen gas via several intermediates, including nitrite and nitrous oxide (Tiedje, 1982). It is recognized as the most important process removing fixed nitrogen in most natural environments (Boicourt et al., 1996). Transformations involve nitrogen reduction and therefore, require electron donors (Devlin et al., 2000). Denitrification is a respiratory process which also requires an electron donor for energy (IslasLimaa et al., 2004). Denitrifying bacteria can use nitrate and/or nitrite as an alternative electron acceptor for metabolic activities when molecular oxygen is unavailable (Bae et al., 2004). However, in natural anaerobic systems including sediments, denitrification often is limited by readily biodegradable electron donors.

Studies have demonstrated enhancement of nitro-reduction rates following addition of organic electron donors, such as glucose, pyruvate, formate, starch, acetate, hydrogen gas, elemental sulphur, thiosulphate, aqueous ferrous iron and pyrite (Preuss et al., 1993; Boopathy, 1994; Roberts et al., 1995; Devlin et al., 2000). 
Saccharide is an abundant biomolecule in the natural environment. Glucose is a monosaccharide, and sucrose is a disaccharide, which yields two monosaccharides upon hydrolysis. Starch contains two polysaccharides: amylose and amylopectin ( $\mathrm{Yu}$ et al., 2004). Acetate is an organic acid and has been used in waste water treatment for nitrogen removal (Graaf et al., 1996; Cervantes et al., 1999).

Addition of electron donors to enhance reduction processes is, therefore, a potential method for in-place treatment of contaminated sediments (Gerlach et al., 1999). This may be an important treatment for eutrophic lakes, such as Lake Taihu, which is the third largest freshwater lake in China (Qin et al., 2007). Water quality in Lake Taihu has deteriorated due to rapid economic development and intensive use of water resources in recent years. As a result, cyanobacteria blooms occur over large areas in summer, and these blooms impact the aquatic ecosystem detrimentally (Pu et al., 1998a, b).

Most studies have focused on nitrate and ammonium removal in waste water systems (Cervantes et al., 2001; Schmidt et al., 2003), and comparative studies on denitrification and electron donor supplements in fresh water sediments are scarce.

Objectives of the present study were to compare total nitrogen $(\mathrm{TN})$ reduction effects in Lake Taihu sediments stimulated by saccharide electron donors, such as glucose, sucrose, potato starch and organic acid acetate; and to evaluate effects of nitrogen species transformation under different electron donor additions.

\section{Materials and methods}

\section{Sediment samples collection}

Six surface sediment samples were collected using a Peterson grab bucket on 13-15 July 2003 from Lake Taihu. Locations of sampling sites are shown in Fig. 1. Samples were stored in a cooler until return to the laboratory, freeze-dried, sieved to $\sim 0.28 \mathrm{~mm}$ aggregate size, mixed together, homogenized by gentle shaking, and stored at $4^{\circ} \mathrm{C}$ in a sealed polyethylene bag.

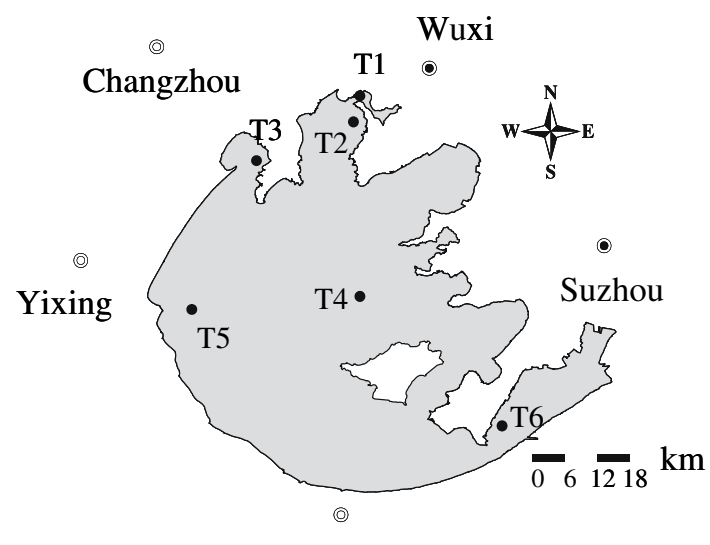

Huzhou

Fig. 1 Geographic locations of sampling sites

Anaerobic incubation experiment

Microcosms were constructed using $20 \mathrm{~g}$ of sediment and $150 \mathrm{ml}$ of artificial freshwater $\left(1 \mathrm{mg} \mathrm{l}^{-1}\right.$ ammonium, $1 \mathrm{mg} \mathrm{l}^{-1}$ nitrate and $0.1 \mathrm{mg} \mathrm{l}^{-1}$ nitrite), which was purged with high purity nitrogen $\left(99.99 \% \mathrm{~N}_{2}\right)$ for $10 \mathrm{~min}$ to remove oxygen before use in 250-ml serum bottles. Microcosms were prepared in triplicate, and electron donors glucose, sucrose, potato starch (Sigma Co.) and sodium acetate added $2 \mathrm{~g}$ in stoichiometric excess. Two electron donor-free control groups, one sterilized with $0.1 \mathrm{~g} \mathrm{HgCl}_{2}$, were established. Table 1 lists the treatment conditions and microcosm abbreviations. Test bottles were aerated with high purity nitrogen for 3-5 additional minutes, sealed with butyl rubber stoppers and continuously mixed with a planar shaker rotating at $200 \mathrm{rpm}$ at $25^{\circ} \mathrm{C}$.

Table 1 Treatment conditions and abbreviations of microcosms

\begin{tabular}{ll}
\hline Abbreviation & Treatment \\
\hline A & Sterilized control \\
B & Electron donor free control \\
C & Microcosm of glucose as electron donor \\
D & Microcosm of sucrose as electron donor \\
E & Microcosm of potato starch as electron \\
& donor \\
F & Microcosm of sodium acetate as electron \\
& donor \\
\hline
\end{tabular}


Sampling was done in a glove bag $\left(\mathrm{I}^{2} \mathrm{R}\right.$ Glove $\mathrm{Bag}^{\mathrm{TM}}$, Model X-27-27, USA) purged with nitrogen before use. Bottles were vigorously shaken; $\mathrm{pH}$ and Eh were determined using a portable meter (Thermo Orion Model 250, USA). Ten milliliter of sediment/water slurry was poured into a $10 \mathrm{ml}$ centrifuge tube, and the same quantity was added (10 $\mathrm{ml}$ artificial freshwater contained $1.33 \mathrm{~g}$ sediment). After sampling, sediment samples were centrifuged at $4000 \mathrm{rpm}$ for $20 \mathrm{~min}$ and filtered through a $0.45 \mu \mathrm{m}$ pore-size cellulose acetate filter to separate sediment and leachate at once.

\section{Chemical analysis}

For leachate samples, ammonium, nitrate and nitrite were determined within $24 \mathrm{~h}$ after sampling. Nitrate was determined by ion chromatography (Dionex 4500i using an AS-14 4-mm anion column), nitrite with $N$-(1-naphthyl) ethylene diamine dihydrochloride (APHA, 1998a), and ammonium with salicylic-hypochlorite colorimetry (Standard method of People's Republic of China, 1987).

Total nitrogen in sediments was analyzed using persulfate according to standard methods for examination of water and wastewater (APHA, 1998b). Weights of sediments reported are on an oven-dry basis.

\section{Results and discussion}

Formal potentials and $\mathrm{pH}$ conditions in the microcosms

Formal potential consists of measurement of the electromotive force of an electrochemical cell in which, under the specified conditions, the analytical concentration of the two oxidation states is varied. The formal potential includes correction factors for activity coefficients, acid-base phenomena, complex formation, and the liquid junction potential used between the reference electrode and the half-cell in question. It may often leads to better predictions than standard potential because it represents quantities subject to direct experimental measurement. In this paper, it is expressed by $\mathrm{p} \varepsilon$, which is calculated from the determined $\mathrm{Eh}$ values using Nernst Equation. The $\mathrm{p} \varepsilon$ can be defined as the negative logarithm of electron activity in a solution. It is a parameter for the redox intensity gives the electron activity at equilibrium and measures the relative tendency of a solution to accept or transfer electrons (Stumm \& Morgan, 1981).

Values of $\mathrm{pH}$ and $\mathrm{p} \varepsilon$ are shown in Fig. 2. In all microcosms, $\mathrm{pH}$ declined with time. Trends are divided into three groups. Microcosms treated with glucose and sucrose had similar trends. $\mathrm{pH}$ declined sharply in the first $96 \mathrm{~h}$ and dropped to 4.3 by completion. $\mathrm{pH}$ in starch additions also declined, but more slowly than glucose and sucrose, dropping to 4.8 at the end of the incubation. $\mathrm{pH}$ in the sterilized control, electron donor-free control and sodium acetate addition declined in the first $48 \mathrm{~h}$, then remained around 7.4 to 7.5 .

Formal potentials in electron donor systems reached a strong reductive environment after 2 or 3 days. $\mathrm{p} \varepsilon$ dropped in the first $48 \mathrm{~h}$ in glucose and sucrose microcosms and in the first $96 \mathrm{~h}$ in starch and sodium acetate microcosms. Afterwards, the
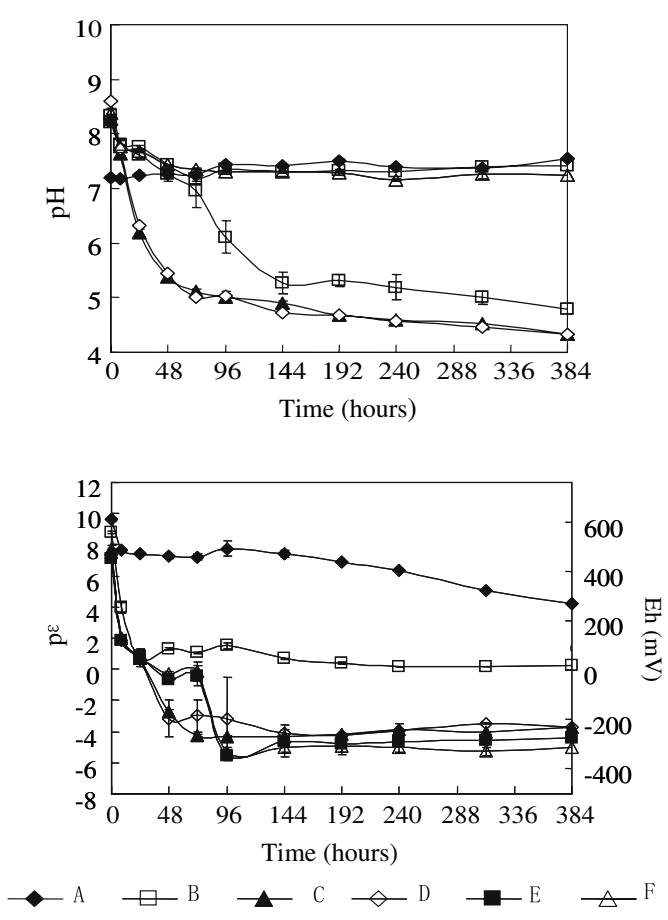

Fig. $2 \mathrm{pH}$ and $\mathrm{p} \varepsilon$ values of microcosms 
reductive environment in these microcosms reached steady-state and remained constant at 4 to -6 . The sterilized control did not attain reductive conditions, and the electron donor-free control barely reached a mild reductive environment.

Systems supplemented with electron donors achieved more reduction potential than controls. It is believed that $\mathrm{Eh}$ values is featured by reduction when they below $200 \mathrm{mV}$. (Song et al., 1990) Sediments from Lake Taihu in our experiment were strongly anaerobic except two control groups, and additional electronic donors could accelerate reducing conditions in microcosms.

$\mathrm{pH}$ and reductive potential are important factors controlling the fate of pollutants, especially those at the soil-water interface (Cao et al., 2001). pH and reductive potential also affect nitrogen composition (Stumm \& Morgan, 1981). $\mathrm{pH}$ in all microcosms treated with electron donors declined, except the system treated with sodium acetate, likely due to acetate hydrolysis. In our experiment, the acetate microcosm may have maintained $\mathrm{pH}$ of 7.2-7.4 via its strong buffering capacity (Terra \& Regel, 1995). However, in other three electron donor microcosms, $\mathrm{pH}$ values declined and remained below 5. At this $\mathrm{pH}$, acid producing microorganisms may not survive, leading to stable $\mathrm{pH}$.

\section{Transformation of nitrogen species}

Nitrogen transformations in control and electron donor microcosms are shown in Figs. 3 and 4. Results show that, in all microcosms, nitrate in leachate increased early in the incubation, then decreased. Nitrate, which is formed during organic matter degradation under oxic conditions (ammonification/nitrification), may be transported (mixing, currents, upwelling etc.) to anoxic environments where it can undergo denitrification (Boyd, 2001). In the present study, early nitrate increases may be caused by degradation of organic matter using residual oxygen in the sediment. For in the first $24 \mathrm{~h}$, formal potential in all microcosms was positive, and $\mathrm{pH}$ was about 7 , indicating characteristics of sediments were weak oxic or weak reduction in this condition.
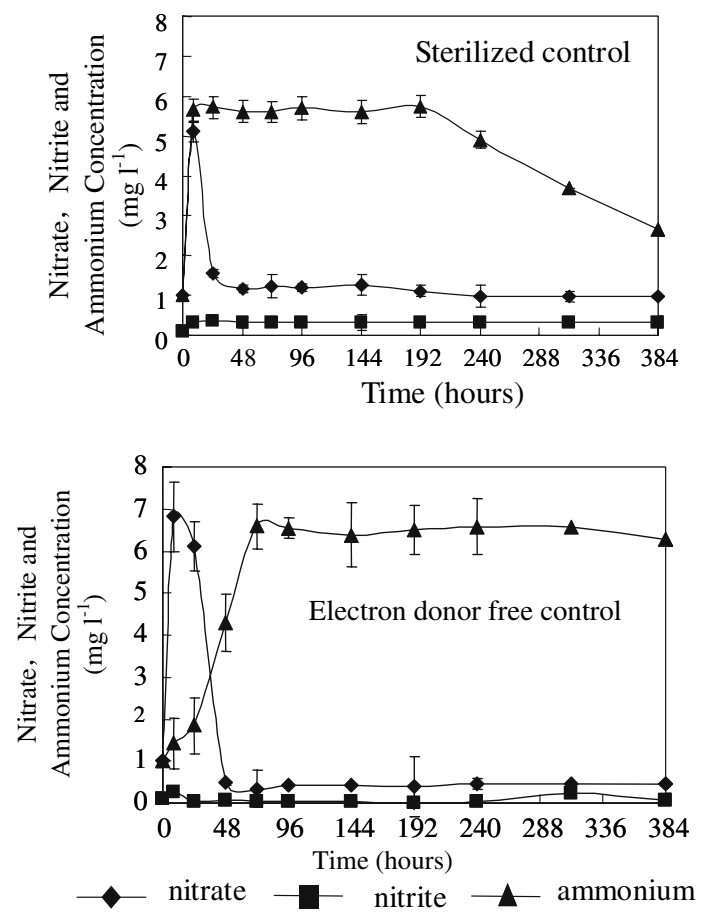

Fig. 3 Transformation of nitrogen species in two control microcosms

Nitrogen transformations in glucose and sucrose microcosms were similar. Nitrate in glucose and sucrose systems were lower than controls. Highest nitrate concentrations in glucose and sucrose microcosms were 5.2 and $4.7 \mathrm{mg} \mathrm{l}^{-1}$, respectively, in the first $8 \mathrm{~h}$ and then decreased sharply. Highest nitrite concentrations in leachate occurred simultaneously with nitrate maxima. Ammonium decreased to below detection limits in $48 \mathrm{~h}$, which indicates that monosaccharide and disaccharide electron donors may stimulate anerobic nitrogen transformations.

Nitrate concentration in the starch addition reached $7.4 \mathrm{mg} \mathrm{l}^{-1}$ in $24 \mathrm{~h}$, and ammonium concentration increased to a similar value as the controls, then decreased to below detection limits after $96 \mathrm{~h}$.

In anoxic, nitrate-containing environments, two pathways of dissimilatory nitrate reduction have been identified: denitrification, by which nitrogen oxides (mainly $\mathrm{NO}_{3}^{-}$) are reduced to nitrite $\left(\mathrm{NO}_{2}^{-}\right)$and then to dinitrogen gases $\left(\mathrm{N}_{2} \mathrm{O}\right.$ and $\mathrm{N}_{2}$ ), and dissimilatory nitrate reduction to ammonia (DNRA), producing ammonia by 

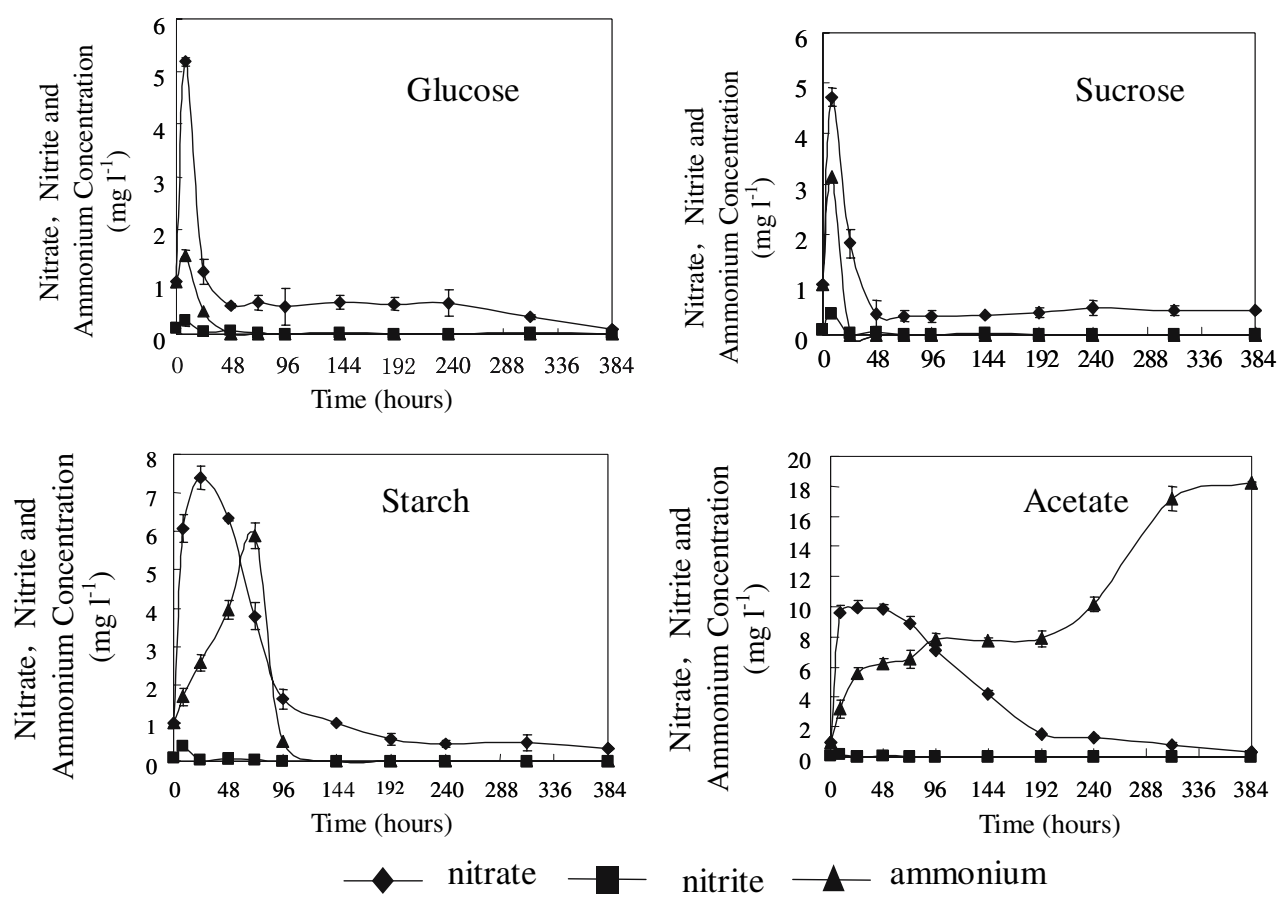

Fig. 4 Transformation of nitrogen species in different electron donor treated microcosms

reduction of nitrate and/or nitrite (Brunet \& Garcia-Gil, 1996).

Apparently, nitrate reduced in microcosms supplemented with glucose, sucrose and starch as electronic donors were denitrified. Ammonium could not be detected after $48 \mathrm{~h}$ in glucose and sucrose systems and $96 \mathrm{~h}$ in the starch system. This indicates that saccharide, including monosaccharide (glucose), disaccharide (sucrose) and polysaccharides (starch), may stimulate nitrate reduction to nitrogen gas, although the dinitrogen gases $\left(\mathrm{N}_{2} \mathrm{O}\right.$ and $\left.\mathrm{N}_{2}\right)$ were not determined in our experiment.

Nitrate and nitrite in the sodium acetate system was different from other electron donor systems. Nitrate in leachate reached $10 \mathrm{mg} \mathrm{l}^{-1}$ and maintained this value for $96 \mathrm{~h}$. Nitrite concentration was half that of glucose and sucrose microcosms. However, ammonium increased to about $8 \mathrm{mg} \mathrm{l}^{-1}$ within $96 \mathrm{~h}$ and remained steady to $240 \mathrm{~h}$. Afterwards, ammonium concentration increased to $18.3 \mathrm{mg} \mathrm{l}^{-1}$ by the end of incubation. Ammonium increased early maybe caused by ammonification of organic matter, for nitrate did not decrease at the first $96 \mathrm{~h}$. But latter the high ammonium value indicated that nitrate was reduced to ammonium in this microcosm. The removal of eight electrons during $\mathrm{NO}_{3}^{-}$reduction to $\mathrm{NH}_{4}^{+}$makes this process potentially advantageous in reduced environments (Tiedje et al., 1982). DNRA may be quantitatively important nitrogen cycling of marine sediments (Sorensen, 1978).

Ammonium concentrations in the control systems were higher than electron donor addition systems except for acetate. Ammonium in the sterilized control increased for $8 \mathrm{~h}$, then remained constant at approximately $6 \mathrm{mg} \mathrm{l}^{-1}$ from $8 \mathrm{~h}$ to $192 \mathrm{~h}$. In the electron donor-free control system, ammonium increased slowly for $192 \mathrm{~h}$. These systems may be controlled by $\mathrm{pH}$ and redox potential. According to $\mathrm{p} \varepsilon \sim \mathrm{pH}$ diagrams (Wang, 2001), at $\mathrm{pH}$ about 7.5 and $\mathrm{p} \varepsilon$ about $0-8$, ammonium is the predominant nitrogen species. This may explain why ammonium in the starch microcosm increased for $96 \mathrm{~h}$ and then decreased to detection limits. $\mathrm{pH}$ and $\mathrm{p} \varepsilon$ conditions in the starch microcosm up to $96 \mathrm{~h}$ were within the ammonium predominance area. And, nitrate reduction seems follow denitrification for $96 \mathrm{~h}$ in 
the starch system since $\mathrm{pH}$ was lower than 6 and $\mathrm{p} \varepsilon$ decreased sharply to about -6 . This condition overstepped the ammonium predominance area. So, nitrate reduction to ammonium stimulated by sodium acetate may be due to comparatively high $\mathrm{pH}$ caused by acetate hydrolysis. In soil, similar results were reported that DNRA was favored at high $\mathrm{pH}$ (Stevens et al., 1998).

TN removal by denitrification

The ability to enhance sediment denitrification via addition of various electron donors was tested in sediment-water microcosms using TN reduction as a gross indicator of denitrification activity. TN removal from sediments in microcosms over $384 \mathrm{~h}$ are shown in Fig. 5. TN removal was observed in all systems but was not significant in the sterilized control, which increased for $48 \mathrm{~h}$, then stayed steady for $384 \mathrm{~h}$. Denitrification in the electron donor-free control increased for $144 \mathrm{~h}$, and TN reduction percentage was $21.8 \%$. Compared to control microcosms, potato starch and sodium acetate systems obtained higher reductive efficiency $(45.5 \%$ and $42.5 \%$, respectively). At the beginning of the incubation, denitrification in glucose and sucrose additions was lower than controls. However, reductive efficiency increased sharply at the end of the incubation $(31.4 \%$ and $34.7 \%$, respectively).

These results demonstrate that additional electronic donors may accelerate. Among the four electron donors, starch and acetate have largest effects. TN reduction ratios of starch and acetate

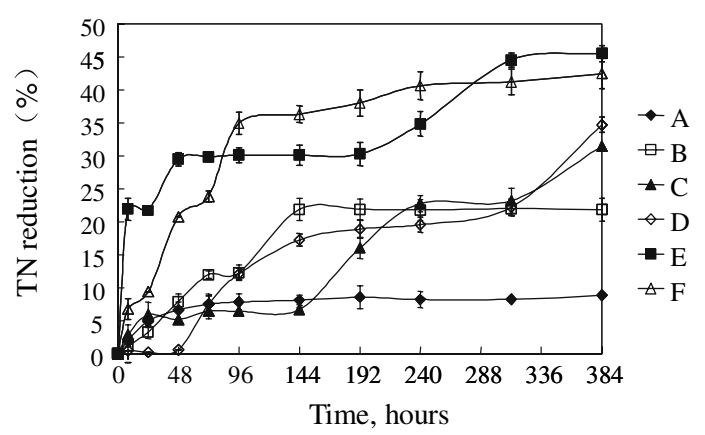

Fig. 5 TN removal ratio of sediments in microcosms were $10 \%$ higher than glucose and sucrose. Since the starch used had low solubility, starch may have been more associated with sediments than the other electron donors (Gerlach et al., 1999) However, TN reduction in the sterilized control increased slightly throughout the experiment, indicating that $\mathrm{HgCl}_{2}$ addition may not have been sufficient to eliminate microbial activity; but the increase in $\mathrm{TN}$ reduction was significantly less than the non-inhibited microcosms. However, this $\mathrm{TN}$ reduction was not observed in the electronic donor-free controls, indicating that either the sterilization agent affected abiotic redox activity, or microorganisms could reduce $\mathrm{TN}$ without electron donor addition.

\section{Conclusions}

The results presented in this paper show certain electron donors may be used to enhance TN removal in anaerobic sediments. Higher nitrogen removal efficiencies were observed when acetate and starch were added. However, nitrogen transformations in anaerobic conditions supplemented with different electron donors varied. Saccharides, such as glucose, sucrose and starch, stimulated nitrate reduction to nitrite, and acetate stimulated nitrate reduction to ammonium. Nitrogen transformations in these microcosms were controlled by $\mathrm{pH}$ and formal potential.

Acknowledgements This work was supported by the Key Project of Chinese Academy of Sciences, (Grant No.KZCX1-SW-12-II-32) and National Key Basic Research Support Foundation of China (Grant No.2002CB412304).

\section{References}

APHA, AWWA \& WEF, 1998a. 4500- $\mathrm{NO}_{2}^{-}$-B Colorimetric Method. Standard Methods for the Examination of Water and Wastewater, 20th edn.

APHA, AWWA \& WEF, 1998b. Persulfate Method. Standard Methods for the Examination of Water and Wastewater, 20th edn, 4500-N C: 4-102.

Bae, H.-S., T. Yamagishi \& Y. Suwa, 2004. An anaerobic continuous-flow fixed-bed reactor sustaining a 3-chlorobenzoate-degrading denitrifying population utilizing versatile electron donors and acceptors. Chemosphere 55: 93-100. 
Boicourt, W. C., W. R. Boynton, T. M. Church, D. M. Ditoro, R. Elmgren, J. H. Garber, A. E. Giblin, R. A. Jahnke, N. J. P. Owens, M. E. Q. Pilson \& S. P Seitzinger, 1996. The fate of nitrogen and phosphorus at the land-sea margin of the North Atlantic Ocean. Biogeochemistry 35: 141-180.

Boopathy, R., 1994. Transformation of nitroaromatic compounds by a methanogenic bacterium, Methanococcus sp. strain B. Archives of Microbiology 162: $167-172$.

Boyd, S. R., 2001. Nitrogen in future biosphere studies. Chemical Geology 176: 1-30.

Brunet, R. C. \& L. J. Garcia-Gil, 1996. Sulfide-induced dissimilatory nitrate reduction to ammonia in anaerobic freshwater sediments. FEMS Microbiology Ecology 21: 131-138.

Cao, X., Y. Chen, X. R. Wang \& X. H. Deng, 2001. Effects of redox potential and $\mathrm{pH}$ value on the release of rare earth elements from soil. Chemosphere 44: 655-661.

Cervantes, F., O. Monroy \& J. Gómez, 1999. Influence of ammonium on the performance of a denitrifying culture under heterotrophic conditions. Applied Biochemistry and Biotechnology 81: 13-23.

Cervantes, F. J., A. David De la Rose \& J. Gómez, 2001. Nitrogen removal from wastewater at low $\mathrm{C} / \mathrm{N}$ ratios with ammonium and acetate as electron donors. Bioresource Technology 79: 165-170.

Devlin, J. F., R. Eedy \& B. J. Butler, 2000. The effects of electron donor and granular iron on nitrate transformation rates in sediments from a municipal water supply aquifer. Journal of Contaminant Hydrology 46: 81-97.

Gerlach, R., M. Steiof, C. L. Zhang \& J. B. Hughes, 1999. Low aqueous solubility electron donors for the reduction of nitroaromatics in anaerobic sediments. Journal of Contaminant Hydrology 36: 91-104.

Graaf, A., P. Bruijin, L. A. Robertson, M. S. M. Jetten \& J. G. Kuenen, 1996. Autotrophic growth of anaerobic, ammonium-oxidizing microorganisms in a fluidized bed reactor. Microbiology 142: 2187-2196.

Islas-Limaa, S., F. Thalassoa \& J. Gómez Hernandezb, 2004. Evidence of anoxic methane oxidation coupled to denitrification. Water Research 38: 13-16.

Pu, P. M., W. P. Hu, G. X. Wang, S. Z. Zhang, C. G. Hu \& J. S. Yan, 1998a. The new strategy for improving the aqua-ecological environmental in Taihu Lake Basin, China. How can we solve the problem of lack of qualified water and deterioration of environment and natural resources in Taihu Lake basin. Journal of Lake Science 10: 47-58 [Suppl].

Pu, P. M., W. P. Hu, J. S. Yan, G. X. Wang \& C. G. Hu, 1998b. A physico-ecological engineering experiment for water treatment in a hypertrophic lake in China. Ecologied Engineering 10: 179-190.
Preuss, A., J. Fimpel \& G. Diekert, 1993. Anaerobic transformation of 2,4,6-trinitrotoluene TNT. Archives of Microbiology 159: 345-353.

Qin, B. Q, P. Z. Xu, Q. L. Wu, L. C. Luo \& Y. L. Zhang, 2007. Environmental Issues of Lake Taihu, China. Hydrobiologia 581: 3-14.

Roberts, D. J., S. Pendharkar \& F. Ahmad, 1995. Factors Affecting TNT Degradation by Anaerobic Consortia. Platform-Presentation, 3rd International Symposium on In Situ and On-site Bioreclamation. San Diego, CA, April 24-27.

Schmidt, I., O. Sliekers, M. Schmid, E. Bock, J. Fuerst, J. G. Kuenen, S. M. Jetten \& M. Strous, 2003. New concepts of microbial treatment processes for the nitrogen removal in wastewater. FEMS Microbiology Reviews 27: 481-492.

Song, J. M., Y. Li \& Z. Zhu, 1990. Relationship between Eh value and redox environment in marine sediments. Marine Science Bulletin 9(4): 33-39.

Sorensen, J., 1978. Capacity for denitrification and reduction of nitrate to ammonia in a coastal marine sediment. Applied \& Environmental Microbiology 35: 301-305.

Standard method of People's Republic of China, 1987. Water quality-determination of ammonium-spectrophotometric method with salicylic acid, GB 748187:211.

Stevens, R. J., R. J. Laughlin \& J. P. Malone, 1998. Soil pH affects the processes reducing nitrate to nitrous oxide and di-nitrogen. Soil Biology and Biochemistry 30: 1119-1126.

Stumm, W., J. J. Morgan, 1981. Aquatic Chemistry: An Introduction Emphasizing Chemical Equilibria in Natural Waters, 2nd edn. John Wiley, Sons, Inc.

Terra, W. R. \& R. Regel, 1995. pH buffering in Musca domestica midguts, comparative biochemistry and physiology Part A. Physiology 112: 559-564.

Tiedje, J. M., 1982. Denitrification. In Page, A. L. (ed.), Methods of Soil Analysis: Part 2. Chemical and Microbiological Properties. 2nd edn. ASA-ASSA, Madison, WI, 1011-1026.

Tiedje, J. M., A. J. Sexstone, D. D. Myrold \& J. A. Robinson, 1982. Denitrification: ecological niches, competition and survival. Antonie Van Leeuwenhoek Journal of Microbiology 48: 569-583.

Wang, K. X., 2001. Aquatic chemistry, Beijing: Chemical Industry Press, Ch.6, Oxidation and Reduction Chemistry, $207 \mathrm{pp}$.

Yu, H., M. Amann, T. Hansson, J. Köhler, G. Wich \& W. F. van Gunsterena, 2004. Effect of methylation on the stability and solvation free energy of amylose and cellulose fragments: a molecular dynamics study. Carbohydrate Research 339: 1697-1709. 